Original Article

\title{
Dissociative disorders: A study of clinico-demographic profile and associated stressors.
}

\author{
Thapa $\mathbf{R}$
}

Consultant Psychiatrist, Neuro Hospital, Biratnagar

\author{
E-mail *Corresponding author: thaparanjan2@gmail.com
}

\begin{abstract}
Objectives: To study relevant clinico-demographic profile and stressors of dissociative disorders. Methods: this is a case control study of 39 cases of dissociative disorders and compared with 39 controls using a self designed questionnaire and G. Singh's Presumptive Stressful Life Events Scale (PSLE). Results: The mean age of the cases was 21.23 years. Cases of Dissociative motor disorders had significantly higher age (26.4 yrs) as compared to dissociative convulsion (18.8 yrs) and dissociative stupor (20.6 yrs). (38.5\%). Two thirds of the cases had comorbid neuropsychiatric illness, the commonest one being depression (35.9\%). The cases had more stressful life events in the past one year as well as whole life when compared to controls. Family conflict was seen to be the commonest precipitating stress. Conclusions: Dissociative disorder mainly affects young people. Dissociative motor disorder is a distinct subtype with a higher age of onset. Presence of neuro-psychiatric co-morbidity is the rule rather than exception. Psychosocial stressors play an important role in disease production.
\end{abstract}

Key words: Dissociative disorder, Co-morbidity, Stressors

\section{INTRODUCTION}

Dissociative disorders manifest as disruptions of the normal integration between memories of the past, awareness of identity and immediate sensations and control of bodily movements. Physical disorders do not explain the symptoms and evidence for underlying psychological factor is required to make a diagnosis of Dissociative disorder. ${ }^{1}$

Epidemiological studies indicate that incidence and prevalence of Dissociative disorder vary across various countries and communities. They are more prevalent in developing countries compared to the developed western countries..$^{2,3}$ Most studies have reported that dissociative disorders occur mostly in people younger than 30 years and the mean age to be 22 to 25 years. $4,5,6$ However Stone and colleague from the UK reported that the mean age of patients with dissociative motor disorders was higher than the mean age of the patients with dissociative convulsion. (39 years vs. 27 years). ${ }^{7}$
Dissociative disorders are frequently associated with other neuropsychiatric comorbidity. ${ }^{8}$ Separate studies from Saudi Arabia, USA and Oman showed that depression was the commonest psychiatric condition associated with dissociative disorder, found in up to $51 \%$ of the cases. ${ }^{4,5,6}$

Previous studies from the western world have reported high incidence of childhood physical and sexual abuse in cases with dissociative disorders. Bowman et al from the USA reported that two thirds of the cases with dissociative convulsions claimed to have childhood sexual and physical abuse.9. Similarly two other studies from USA have reported that cases of dissociative disorders reported childhood sexual and physical abuse rates as high as $80 \% .10,11$

On the backdrop of above issues, this study was conducted to know if dissociative disorders occur in the same age group in Nepal as in other countries and is there a difference in the age of onset of dissociative motor disorder in Nepal as well. We also tried to study if dissociative disorders had the same 
pattern of co-morbidity in Nepal. Likewise we wished to investigate what types of stressors are involved in dissociative disorders in Nepal and what is the level of childhood physical and sexual abuse among our cases.

\section{MATERIAL AND METHOD}

This is a general hospital based case control study conducted in the eastern part of Nepal.

\section{Instruments:}

1) A Semi-structured, self-designed questionnaire inquiring about the sociodemographic variables, dissociative symptoms, psychiatric co-morbidity, associated physical illnesses, duration of illness and significant past and family history.

2) Presumptive Stressful Life Events Scale (PSLE) by G. Singh (1983) ${ }^{13}$

This scale was developed by Gurmeet Singh and co-workers in 1983. It has 51 items related to various stressful life events in the life of an individual relevant in our culture and was administered in semi structured interview manner. It taps desirable, undesirable and ambiguous life events in last one year and for whole life. It gives an individual stress score and cumulative stress score for computation.

\section{Methods:}

The study group consisted of patients presenting with dissociative disorder in the emergency room and the psychiatry OPD. The patients who did not give consent to take part in the study or who had any discernible physical illness were excluded from the study. The patient's social and demographic variables were recorded using a semistructured proforma. Detailed evaluation was done to document the clinical features of dissociative symptoms as well as to assess other co-morbid psychiatric illness. The interview also included inquiry about physical and sexual abuse in the past. Patients were then administered the Presumptive Stressful Life Events Scale. The events were retrospectively assessed for the last one year as well as for the whole life of the patient.

Normal age and sex matched controls were enrolled from among the visitors of the psychiatric patients. People who had any discernible psychiatric illness were excluded from the control group. The Presumptive
Stressful Life Events Scale was administered in an identical manner to the control group.

\section{Statistical Analysis:}

Standard error of the mean was used for comparison of continuous data between two groups. Chi- square test was used for test of significance. Analyses were done using SPSS version 10.0 .

\section{RESULT}

A total of 39 patients with a diagnosis of dissociative disorder presenting to BPKIHS and 39 normal controls were included in the study.

Table 1. Age group distribution of cases and controls

\begin{tabular}{|l|l|l|}
\hline $\begin{array}{l}\text { Age group } \\
\text { (Years) }\end{array}$ & $\begin{array}{l}\text { Cases } \\
\mathbf{N}=39(\%)\end{array}$ & $\begin{array}{l}\text { Control } \\
\mathbf{N}=39(\%)\end{array}$ \\
\hline $10-19$ & $23(58.9 \%)$ & $14(36 \%)$ \\
\hline $20-29$ & $10(25.6 \%)$ & $20(51.3 \%)$ \\
\hline $30-39$ & $4(10.2 \%)$ & $5(12.8 \%)$ \\
\hline $40-49$ & $2(5.1 \%)$ & 0 \\
\hline $50-59$ & 0 & 0 \\
\hline $60+$ & 0 & 0 \\
\hline
\end{tabular}

Table 2. Mean age of cases and controls

\begin{tabular}{|l|l|l|l|}
\hline & $\begin{array}{l}\text { Cases } \\
(\mathbf{N}=39)\end{array}$ & $\begin{array}{l}\text { Controls } \\
(\mathbf{N = 3 9 )}\end{array}$ & P value \\
\hline Mean age & 21.23 & 23.18 & 0.176 \\
SD & 7.227 & 5.206 & \\
\hline
\end{tabular}

There is no significant difference in the mean age between the cases and controls. Around $84.5 \%$ of the cases with Dissociative disorder were less than 30 years of age. Only $5.1 \%$ of the patients were 40 years or older in age. The age of the patients with dissociative disorder ranged from 14to 40 years.

Table 3. Age of onset

\begin{tabular}{|l|l|}
\hline Minimum age of onset & 8 years \\
\hline Maximum age of onset & 40 years \\
\hline Mean age of onset & 19.10 \\
\hline SD & 6.34 \\
\hline
\end{tabular}


Table 4. Subtype of dissociative disorder and age at presentation

\begin{tabular}{|l|l|l|l|l|}
\hline Subtype & N & $\begin{array}{l}\text { Mean } \\
\text { Age } \\
\text { (Years) }\end{array}$ & SD & $\begin{array}{l}\text { P } \\
\text { value }\end{array}$ \\
\hline $\begin{array}{l}\text { Dissociative } \\
\text { convulsion }\end{array}$ & 15 & 18.80 & 5.62 & \\
\cline { 1 - 3 } $\begin{array}{l}\text { Dissociative } \\
\text { motor } \\
\text { disorder }\end{array}$ & 10 & 26.40 & 9.28 & \multirow{2}{*}{0.02} \\
\cline { 1 - 3 } $\begin{array}{l}\text { Dissociative } \\
\text { stupor }\end{array}$ & 12 & 20.6 & 5.21 & \\
\hline
\end{tabular}

Table 4 shows that the mean age of the patients with Dissociative motor disorder was highest (26.40 years), followed by those with dissociative stupor (20.6 years) and Dissociative convulsion (18.8 years). This difference was statistically significant $(p=0.02)$.

\section{Co- morbidity in cases with dissociative disorders}

It was seen that $33.3 \%$ of the cases had no associated co-morbidity. Depression was the commonest psychiatric co-morbidity (35.9\%), followed by migraine $(10.3 \%)$, histrionic personality disorder $(10.3 \%)$, borderline personality disorder $(7.7 \%)$, anxious personality disorder (5.1\%), panic disorder $(2.6 \%)$, generalized anxiety disorder $(2.6 \%)$, and mental retardation (2.6\%). There were four cases $(10.3 \%)$ with multiple comorbidities.

\section{Recent stressful life events}

The commonest stress was family conflict (23.1\%). Other common stressors were broken affair $(7.7 \%)$, death of family member $(7.7 \%)$, conflict with in laws $(5.1 \%)$, failure in exams (5.1\%), physical illness/injury (5.1\%), approaching exams (2.6\%), sexual assault $(2.6 \%)$, and threat by rebels $(2.6 \%)$. In about one fourth case no stressor could be elicited.

Table 5. Abuse in childhood

\begin{tabular}{|l|l|l|}
\hline & $\begin{array}{l}\text { Positive } \\
\text { number (\%) }\end{array}$ & $\begin{array}{l}\text { Negative } \\
\text { number (\%) }\end{array}$ \\
\hline $\begin{array}{l}\text { Physical abuse } \\
\text { in childhood }\end{array}$ & $2(5.1 \%)$ & $37(94.6 \%)$ \\
\hline $\begin{array}{l}\text { Sexual abuse } \\
\text { in childhood }\end{array}$ & $1(2.6 \%)$ & $38(97.4 \%)$ \\
\hline
\end{tabular}

Table 6. Comparison of life events between cases and controls

\begin{tabular}{|c|c|c|c|c|c|c|}
\hline & Group & $\mathrm{N}$ & Mean & SD & $\begin{array}{l}\text { Std } \\
\text { error }\end{array}$ & $\begin{array}{l}\mathrm{P} \\
\text { value }\end{array}$ \\
\hline $\begin{array}{l}\text { Life } \\
\text { event } \\
\text { scores } \\
\text { (1yr) }\end{array}$ & $\begin{array}{l}\text { Cases } \\
\text { Controls }\end{array}$ & $\begin{array}{l}39 \\
39\end{array}$ & $\begin{array}{l}88.46 \\
36.95\end{array}$ & $\begin{array}{l}44.45 \\
24.02\end{array}$ & $\begin{array}{l}7.11 \\
3.84\end{array}$ & 0.0001 \\
\hline $\begin{array}{l}\text { No of } \\
\text { events } \\
\text { (1yr) }\end{array}$ & $\begin{array}{l}\text { Cases } \\
\text { Controls }\end{array}$ & $\begin{array}{l}39 \\
39\end{array}$ & $\begin{array}{l}1.79 \\
0.82\end{array}$ & $\begin{array}{l}0.92 \\
0.50\end{array}$ & $\begin{array}{l}0.15 \\
0.81\end{array}$ & 0.0001 \\
\hline $\begin{array}{l}\text { Life } \\
\text { events } \\
\text { scores } \\
\text { (whole } \\
\text { life) }\end{array}$ & $\begin{array}{l}\text { Cases } \\
\text { Controls }\end{array}$ & $\begin{array}{l}39 \\
39\end{array}$ & $\begin{array}{l}150.3 \\
74.62\end{array}$ & $\begin{array}{l}94.02 \\
35.19\end{array}$ & $\begin{array}{l}15.05 \\
5.63\end{array}$ & 0.0001 \\
\hline $\begin{array}{l}\text { No of } \\
\text { events } \\
\text { (whole } \\
\text { life) }\end{array}$ & $\begin{array}{l}\text { Cases } \\
\text { Controls }\end{array}$ & $\begin{array}{l}39 \\
39\end{array}$ & $\begin{array}{l}3.26 \\
1.74\end{array}$ & $\begin{array}{l}1.87 \\
0.93\end{array}$ & $\begin{array}{l}0.30 \\
0.15\end{array}$ & 0.0001 \\
\hline
\end{tabular}

Table 6 shows that the mean no of stressful life events during the last one year as well as the whole life was significantly more among the cases than among the controls. Similarly the stressful life event score during the last one-year as well as the whole life was found to significantly more among the cases than among the controls.

\section{DISCUSSION}

In this study we investigated the sociodemographic profiles, the specific symptoms, neuropsychiatric co-morbidities, stressful life events, and childhood physical or sexual abuse among patients with dissociative disorders. We also compared the stressful life events score of these patients with age and sex matched healthy controls.

The mean age of cases in our study was 21.23 years. The majority of the patients $(84.5 \%)$ were less than 30 years of age. The mean age of onset was found to be 19.10 years. The mean age of the patients also showed variation according to the subtype of dissociative disorder. The patients with dissociative convulsion were youngest at a mean age of 18.8 years while the mean age of patients with dissociative motor disorder was highest at 26.6 years and the mean age of the patients with dissociative stupor was intermediate at 20.6 years. This finding is consistent with the findings from other studies. A study from Oman reported that the mean age of the 
patients with dissociative disorders was 22.4 years and about $80 \%$ of the patients were less than 30 years of age. ${ }^{6}$ Comparable findings were reported in another study conducted in Saudi Arabia. In that study it was reported that $80 \%$ of the patients with dissociative disorders were less than 30 years of age. 4 Notably a study from Sweden reported that the mean age of the patients with dissociative motor disorders was 38.8 years. ${ }^{12}$ Similarly Stone and colleagues have reported from the UK that the mean age of patients with motor conversion disorder to be higher at 39 years. $^{7}$ In the same study the mean age of the patients with dissociative seizures was found to be 27 years. ${ }^{8}$ Based on the findings of our study and previous study we suggest that Dissociative disorder occurs mostly in people below 30 years of age. We also suggest that patients with dissociative motor disorder represent a distinct subgroup with a higher age of onset although we are not able to suggest any particular reason for this.

Dissociative disorders are frequently associated with other neuropsychiatric comorbidity..$^{8}$ Our study revealed that two thirds of the patients with dissociative disorders had at least one neuropsychiatric co-morbidity. One or another axis I disorder was associated with $51.3 \%$ cases of dissociative disorders. Among the axis I disorders depression was the commonest co-morbidity. It was seen in 35.9\% of the cases. Similar results were obtained by other studies from different parts of the world. Separate studies from Saudi Arabia, USA, Oman and India showed that depression was the commonest psychiatric condition associated with dissociative disorder. $4,5,6,16$ The highest rate of co-morbid depression was reported by a study from the USA, which reported that depression was associated with $51 \%$ of the cases with dissociative disorder. ${ }^{5}$

One or other co-morbid axis II illness was seen in $25.6 \%$ of the cases. In our study among the axis II disorders, Histrionic personality disorder was the commonest disorder associated with $10.3 \%$ of the cases. Similar result was seen in one study conducted in Saudi Arabia where personality disorder was reported to be present in $10 \%$ of the cases with dissociative disorder; among them half were found to be histrionic. ${ }^{4}$ Whereas other studies, especially from the developed countries have reported rather higher rates of co- morbid personality disorder. For instance one study from Sweden reported that about half of the patients with dissociative disorder had personality disorder while another study from Turkey reported that borderline personality disorder to be present in two thirds of the cases with dissociative disorder. ${ }^{12,17}$ Yet another study conducted by Bowman and Markland in the USA showed that personality disorder was present in $62 \%$ of the cases with dissociative disorder. ${ }^{9}$ So there seems to a geographical variation in the rate of co-morbid personality disorder. We are not able to suggest any particular reason for this variation. One possible reason might be the higher prevalence of personality disorders itself in these developed countries.

About $75 \%$ of cases had some precipitating stress. The most common type of stress described by our patients was family conflict (23.1\%), followed by broken affair and death of a family member (7.7\% each). These findings are consistent with findings from other studies. For example Habeeb, and coauthors reported from Saudi Arabia that $67.5 \%$ of the cases with dissociative disorders had some antecedent stress. ${ }^{4}$ Similarly in a study from Oman precipitating stress was reported by $62.9 \%$ of the cases with dissociative disorders, the commonest one being family conflict $(20.7 \%)$, followed by academic difficulty $(18 \%)$, conflict with people other than family members $(8 \%)$ and work related problems $(8 \%)^{6}$ Gaw, Ding and Livine reported from China one or the other precipitating stress was present in all cases with dissociative disorders and the most prevalent stressful event was interpersonal conflicts $(30)^{6}$ Other studies conducted in different settings have reported high incidence of childhood sexual and physical abuse among patients with dissociative disorders. Bowman et al revealed from the USA that abuse was reported by majority of the subjects with dissociative disorders: sexual abuse by $67 \%$, and physical abuse by $67 \% .{ }^{9}$ Similarly one community based study from New Zealand reported that childhood sexual abuse was two times more common and childhood physical abuse was five times more common in cases of dissociative disorders as compared to normal controls. ${ }^{15} \mathrm{Chu}$ and colleagues reported that among 98 cases with dissociative symptoms $63 \%$ reported childhood physical and/or sexual abuse. ${ }^{11}$ However in our study only one patient $(2.6 \%)$ reported sexual abuse during childhood and only two patients (5.1\%) reported physical abuse during childhood. 
This finding suggests that childhood abuse and personality disorders may not be important factors in production of dissociative symptoms in our country. Here other stressors like family conflict and economic difficulties are more important precipitating factor for the development of dissociative features. The lower rate of childhood abuse, particularly sexual abuse report could also be due to embarrassment as the topic with sexual content is still considered as taboo in our context.

Previous studies have shown that life events in the last one-year are related to dissociative disorders. For example one study conducted in the USA revealed that stressful life events were reported more in cases with dissociative convulsions as compared to the controls. 5 Another study conducted in Sweden showed that among the patients with Dissociative disorders the average no of life events occurring in the last one year was 2.7 in comparison to 1.67 in the control. ${ }^{12}$ In agreement to former studies we found that the mean no of stressful events occurring in the last one year as well as in the whole life of the cases with dissociative disorders was significantly more in comparison to the controls. This suggests that not only the stresses facing the patients immediately prior to the illness but also the stressful life events faced by them throughout their lives contribute to the development of dissociative disorders. It seems likely that when people facing multiple stressful events in their life are challenged by an insurmountable stressor they may develop a dissociative illness.

In conclusion this study revealed that dissociative motor disorder has a distinctly higher age of onset than other subtypes. It also found that although depression is the commonest co-morbidity among the cases with dissociative disorder as in other parts of the world, co-morbid personality disorder is much less prevalent in our setting as compared to the west. This study also demonstrated the role of stressful life events in the development of dissociative disorder. Although studies from the west have revealed high level of childhood physical and sexual abuse among the cases of dissociative disorder, our study did not show similar findings suggesting that other stressors may be more common precipitating factors for dissociative disorder.

\section{Limitations of the study}

This study reports cross-sectional data from cases attending hospital only. Hence we cannot be sure that the results can be generalized to the whole community.

\section{REFERENCE}

1. World Health Organization: The ICD-10 Classification of Mental and Behavioral Disorders: Clinical Descriptions and Diagnostics Guidelines. World Health Organization, Geneva; 2002. Pp 151-161.

2. Nandi DN, Banerjee G, Nandi S, Nandi P: Is hysteria on the wane? A community survey in West Bengal, India. $\mathrm{Br} \mathrm{J}$ Psychiatry, 1992 Jan; 160: 87-91.

3. Stefansson JG, Messina JS, Meyerowitz S: Hysterical neurosis, conversion type: clinical and epidemiological considerations. Acta Psychiatr Scand 1976; 53:119-138.

4. Habeeb T, Al-Zaid K, Rahim F, Al-Farris EA: Hysteria: A clinical and sociodemographic profile of 40 patients admitted to a teaching hospital, 1985-1995. Ann Saudi Med 1997; 17(1): 35-38.

5. Tina M, Tojek MA, Lumley M: Stress and other psychosocial characteristics of patients with psychogenic NES. Psychosomatics 2000 June; 41: 221-226.

6. Chand SP, Al-Hussaini AA, Martin R, Mustapha, Zaidan Z, Viernes N, Al-Adawi S: Dissociative Disorders in the Sultanate of Oman. Acta Psychiatr Scand 2000; 102: 185-187.

7. Stone J, Sharpe M, Binzer M: Motor Conversion Disorder and Pseudoseizures: a comparison of clinical characteristics. Psychosomatics 2004; 45(6): 492-499.

8. Merskey H: 'Conversion and Dissociation' In Gelder et al's New Oxford textbbook of Psychiatry, Vol I, 1st edition (ed Michael G. Gelder, Juan J Lopez-Ibor, Nancy Andreason), Oxford University Press, 2000. pp 1088-1094.

9. Bowman ES, Markland ON: Psychodynamics and psychiatric diagnosis of pseudoseizure subjects. Am J Psychiatry 1996 Jan; 153(1): 57-63.

10. Chu JA, Frey LM, Ganzel BL, Matthews A: Memories of childhood abuse: Dissociation, Amnesia, and Corroboration. Am J Psychiatry 1999; 156:749-755.

11. Chu JA, Dill DL: Dissociative Symptoms in Relation to Childhood Physical and Sexual Abuse: Am J Psychiatry 1990; 147: 887-892.

12. Binzer M, Andersen PM, Kullgren G: Clinical characteristics of patients with motor disability due to Conversion 
Disorder: a prospective control group study. J Neurol Neurosurgery Psychiatry 1997; 63: 83-88.

13. Singh G et al: Presumptive Stressful Life Events Scale (PSLES). Indian Journal of Clinical Psychology 1981; 8:17.

14. Uguz S, Toros F: Sociodemographic and clinical characteristics of patients with conversion disorder. Turk Psikiyatri Derg, 2003; 14(1): 51-58

15. Mulder RT, Beautralis A, Joyce PR, Ferguson DM: Relation between Dissociation, Childhood Sexual Abuse, and mental Illness in a general Population Sample. Am J Psychiatry 1998; 155: 806811.

16. Roy A: Hysteria: a case study note. Can J psychiatry 1979; 74(2): 157-160.

17. Tutkun H, Sar V, Yargic I, Ozpulat T, Yanik M, Kizilitan E: Frequency of Dissociative Disorders among psychiatry inpatients in a Turkish University Clinic. Am J Psychiatry 1998; 155:800-805.

18. Gaw A, Ding QZ, Livine R, Gaw HF: The clinical characteristics of Possession Disorder among 20 Chinese patients in the Hubei Province of China. Psyhiatr Serv 1998; 49: 360-365. 